\title{
Drug Withdrawn
}

National Cancer Institute

\section{Source}

National Cancer Institute. Drug Withdrawn. NCI Thesaurus. Code C49502.

An indication that a medication schedule was modified through termination of a prescribed regimen of medication. 